\title{
Advances in cancer therapy through the use of carbon nanotube-mediated targeted hyperthermia
}

This article was published in the following Dove Press journal:

International Journal of Nanomedicine

I2 August 201 I

Number of times this article has been viewed

\section{Cornel lancu \\ Lucian Mocan \\ 3rd Surgery Clinic, Department of Nanomedicine, "luliu Hatieganu" University of Medicine and Pharmacy, Cluj-Napoca, Romania}

\begin{abstract}
Carbon nanotubes (CNTs) are emerging versatile tools in nanomedicine applications, particularly in the field of cancer targeting. Due to diverse surface chemistry and unique thermal properties, CNTs can act as strong optical absorbers in near infrared light where biological systems prove to be highly transparent. The process of laser-mediated ablation of cancer cells marked with biofunctionalized CNTs is frequently termed "nanophotothermolysis." This paper illustrates the potential of engineered CNTs as laser-activated photothermal agents for the selective nanophotothermolysis of cancer cells.
\end{abstract}

Keywords: carbon nanotubes, cancer targeting, functionalization, optical excitation, cancer treatment

\section{Introduction}

During the past decade advances in fuctionalization chemistry have been one of the driving forces in the development of new classes of novel nanomaterials for applications in biology and medicine..$^{1-8}$

Carbon nanotubes (CNTs), with their unique physical and chemical properties, hold great promise for drug delivery and cancer therapy. ${ }^{9}$ The research mechanisms of selective tumor targeting with biofunctionalized CNTs are currently being intensely explored due to their impressive ability to convert near-infrared (NIR) laser radiation into heat. This intrinsic property opens new avenues for the development of novel immunoconjugates for cancer phototherapy with high performance and efficacy in the selective thermal ablation of malignant cells. ${ }^{10,11}$ This method is based on the intracitoplasmatic internalization and clustering of CNTs and their highly optical absorbtion under NIR laser radiation where the biological systems have low absorption and high transparency. ${ }^{12}$ The optoelectronic transitions in the graphitic structures of the CNTs clusters generate thermal energy ${ }^{13}$ that rapidly diffuses into the various cell compartments, where the CNTs are present, with consequent cell necrosis.

The development of targeted therapy represents an exciting and new approach to cancer treatment. ${ }^{14}$ Conceptually, a targeted drug represents a responsive molecule attached to a delivery carrier with affinity for specific surface receptor proteins located in cell membranes. ${ }^{15-17}$ Being endowed with target specificity, the carrier is able to concentrate only in the desired biological area. The use of these biological carriers for the development of specific and sensitive site-targeted bionanosystems makes possible the selective internalization of molecules with photothermal properties in cancer cells. This internalization process is not possible under normal conditions. ${ }^{18,19}$ 
Therefore, such bioconjugation holds tremendous potential for future cancer treatment. However, $100 \%$ selective internalization of nanobioconjugates in the cancer cells remains problematic. ${ }^{20,21}$ While progress has been made in biofunctionalization of CNTs using various biological molecules such as polyethylene glycol (PEG), DNA, antibodies, folates, cytostatic drugs, and growth factors, ${ }^{22-27}$ there is a significant lack of knowledge on how to obtain selectivity these compounds for a single type of cancer cell. This lack is due to the simultaneous presence of the receptors used for the specific binding of the targeting molecules to the membranes of the noncancerous cells, although in smaller amount than the cancer cells. ${ }^{28-31}$

Photothermal ablation of malign cells containing intracytoplasmatic CNTs may be used in two main modes: pulsed and continuous. The first mode produces localized (a few micrometers) necrosis of individual cancer cells by thermal micro- and nanobubbles around overheated nanoparticles without harmful effects on the surrounding cells. The pulsed mode produces in vivo killing of single circulating tumor cells using just one-nanosecond laser pulses. The second mode lasts longer (several minutes of exposure) and produces cell damage through nuclear fragmentation and organelles disintegration. It is recommended for the treatment of primary tumors measuring a few millimeters. ${ }^{12,32}$

In this review, we first summarize the current progress in the use of CNTs for the in vitro selective photothermal abation of cancer cells studies as well as pioneering efforts towards in vivo and ex vivo therapies.

\section{Intracellular internalization of CNTs}

Various mechanisms for the internalization pathway of single-walled CNTs (SWCNTs) inside living cells have been proposed. Pantarotto et $\mathrm{al}^{33}$ suggested that insertion and diffusion of nanotubes across cell membranes is an energy-independent nonendocytotic process. In contrast, other reports showed that transmembranar transport of SWCNTs conjugates with proteins and DNA is through the clathrin-dependent endocytosis pathway. ${ }^{34}$ However these controversies on the internalization mechanism were explained by several differences in both the nanotube material and experimental procedures that were used in these two studies. ${ }^{35}$ It has been stated that a proficient method needed to minimize toxic effects and also to increase the level of therapeutic response for CNTs, is represented by their conjugation to a carrier molecule..$^{25,35-42}$ For instance, various strategies for the fabrication of nanomoieties to target folate receptors on the cancer cell membrane have been proposed. ${ }^{12}$ Folate receptors are overexpressed in cancer and their targeting allows CNTs to facilitate cellular internalization of folatecontaining species by receptor-mediated endocytosis ${ }^{43}$ which is more selective than CNTs alone that enter cells through phagocytosis or endocytosis and through passive diffusion.

\section{In vitro nanophototermolysis of tumors mediated by CNTs}

The first in vitro published observation of the potential of CNTs with very high optical absorbance in the NIR regime (where biological systems are transparent) such as photothermal vectors ${ }^{12}$ stimulated significant interest and research, leading to rapid development in the field (Figure 1).

\section{In vitro nanophotothermolysis of cervical cancer}

In one study, HeLa cells with internalized SWCNTs conjugated to single strand DNA were irradiated under a $1.4 \mathrm{~W} / \mathrm{cm}^{2}$ power laser. ${ }^{12}$ Notably, these authors reported extensive cell death after 2 minutes of radiation suggested by cell morphology changes, loss of attachment, and aggregation of organelles debris. Raman spectroscopy and scanning electron microscopy identified SWCNTs mixed with cell debris in the black aggregates and confirmed that local heating was the most likely origin of cell death. In contrast, cells without exposure to SWCNTs survived continuous $3.5 \mathrm{~W} / \mathrm{cm}^{2}$, $808 \mathrm{~nm}$ laser radiation for 5 minutes.

In a study conducted by Biris et al, advanced IR thermography was used for the remote measuring the laser-induced photothermal effects of HeLa cells exposed to the 1064-nm laser irradiation before and after the cells were incubated with CNTs for 48 hours. ${ }^{44}$ IR thermal analysis studies performed before the cells were incubated with CNTs indicated that no notable temperature variation $\left(<1.5^{\circ} \mathrm{C}\right)$ was induced by the laser radiation. When HeLa cells were incubated with the CNTs for 48 hours, the authors showed that intracellular heat dramatically increased after laser irradiation.

\section{In vitro nanophotothermolysis of prostate cancer}

In a study conducted by Fisher et al, human prostate cancer (PC3) cells were irradiated with a $1064 \mathrm{~nm}$ laser with an irradiance of $15.3 \mathrm{~W} / \mathrm{cm}^{2}$ for two heating durations $(1.5$ and 5 minutes) alone or in combination with internalized multiwalled CNTs (MWCNTs). ${ }^{45}$ Cytotoxicity tests and heat shock proteins expression following laser heating were used to determine the efficacy of laser treatment alone or in 

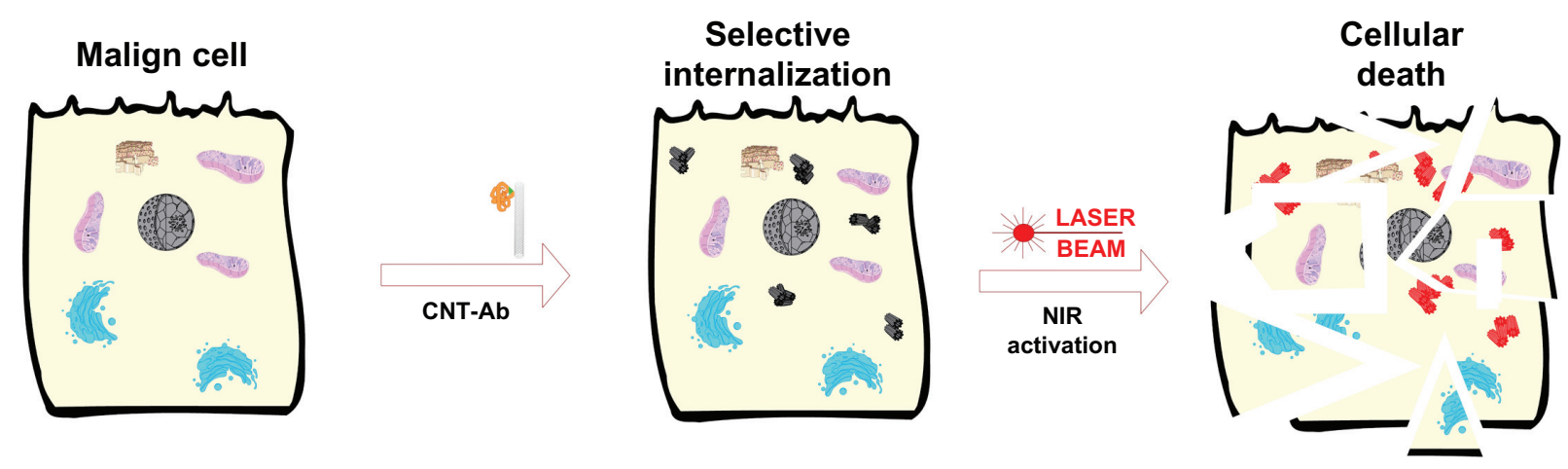

Figure I Schematic illustration of in vitro selective photothermal ablation of cancer by laser activated intracellulary biofunctionalized carbon nanotubes. Abbreviations: Ab, antibody; CNT, carbon nanotube; NIR, near-infrared.

combination with MWCNTs. The authors found that cell viability dramatically decreased after laser irradiation. When cells were incubated longer, a greater number of MWCNTs were observed at transmission electron micrograph (TEM) analysis in cellular vacuoles and nuclei.

\section{In vitro nanophotothermolysis of brain cancer}

The photothermal anticancer activity of NIR-excited graphene nanoparticles and CNTs were compared for induction of photothermal necrosis of U251 human glioma cells in vitro. ${ }^{46}$ In this approach, the glioma cells were treated with carbon nanoparticles $(2.5-10 \mu \mathrm{g} / \mathrm{mL})$ and further exposed to NIR irradiation $\left(808 \mathrm{~nm}, 2 \mathrm{~W} / \mathrm{cm}^{2}\right)$ for different periods of time (30-300 seconds). As result, both carbon nanoparticles displayed a dose-dependent and time-dependent totoxicity on U251 cells. Notably, the graphene nanoparticles were several-fold more efficient in photothermal killing of glioma cells than CNTs bound to DNA at the same concentrations. The patterns of graphene-mediated photothermal necrosis proved to involve oxidative stress and mitochondrial membrane depolarization with consequent caspase activation/ DNA fragmentation.

Glioblastoma GBM-CD133 (+) and GBM-CD133 (-) cells were incubated with SWCNTs conjugated with CD133 monoclonal antibody (anti-CD133) and then irradiated with NIR laser light. ${ }^{47}$ Results showed that GBM-CD133 (+) cells were selectively targeted and destroyed, while GBM-CD133 (-) cells remained viable. In addition, the authors proved that in vitro tumorigenic and self-renewal capability of GBM-CD133 (+) treated with localized hyperthermia was significantly reduced. To that end, the GBM-CD133 (+) cells pretreated with antiCD133-SWCNTs and irradiated by NIR laser 2 days after xenotransplantation in nude mice did not exhibit sustainability of cancer stem cell features for tumor growth. The thermal energy produced by NIR-activated CD-SWCNTs was sufficient to destroy GBMD133+ cells xenotransplanted in mice and consequently to stop tumor growth.

In order to specifically target disialoganglioside (GD2) receptors on the surface of neuroblastoma stNB-V1 cells, GD2 monoclonal antibody (anti-GD2) was conjugated to CNTs. ${ }^{41}$ After the treatment of neuroblastoma cells with anti-GD2 conjugated CNTs for 6 hours, the cells were further irradiated with an $808 \mathrm{~nm}$ NIR laser with intensity increasing from 0.6 to $6 \mathrm{~W} / \mathrm{cm}^{2}$ for 10 minutes which was then maintained at $6 \mathrm{~W} / \mathrm{cm}^{2}$ for an additional 5 minutes. Post-NIR laser exposure and after being examined by calcein-AM dye, stNB-V1 cells were all foud to be necrotic, while non-GD2 expressing PC12 cells (control) remained viable.

\section{In vitro nanophotothermolysis of liver cancer}

Recently, considering the important role of human serum albumin (HSA) in tumor metabolism ${ }^{48-51}$ (since it is used for the synthesis of various cellular substrates), we have bound human albumin to MWCNTs for the selective targeting of liver cancer cells. ${ }^{52}$ Most data show that caveolae-mediated endocytosis in cells is activated by the binding of albumin to a specific endothelin receptor gp60, a receptor located in the caveolae. ${ }^{53}$ In this work, using confocal (Figure 2) and TEM, we showed that the mechanism of HSA-MWCNTs uptake in HepG2 cells occurs through caveolae-dependent endocytosis initiated by the selective binding of HSA-MWCNTs to gp60 receptor called albondin. To accomplish this, we treated the cells with $5 \mathrm{mg} / \mathrm{L} \mathrm{HSA}$-MWCNTs marked with fluorescein isothiocyanate (FITC) for 1 hour followed by incorporation of cy3anti-gp60 antibody for 30 minutes at $37^{\circ} \mathrm{C}$. Further, we showed that HepG2 cells internalized with albumin-bound MWCNTs (fluorescently marked with FITC) were distributed into a green punctate structure inside the cells (Figure 2A, second panel). 

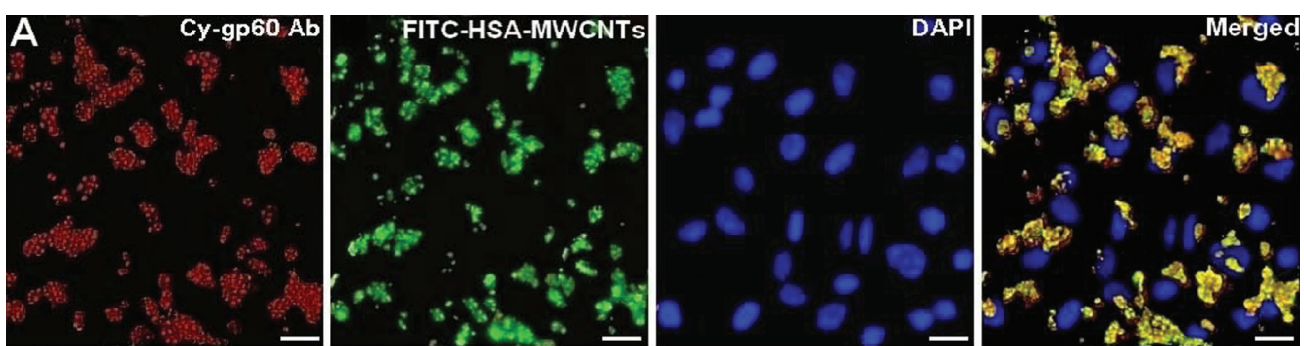

Hep G2
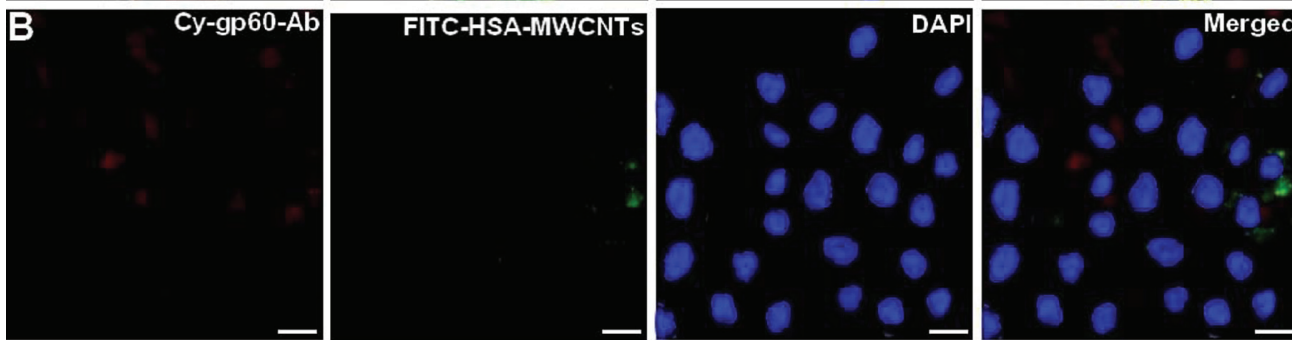

d
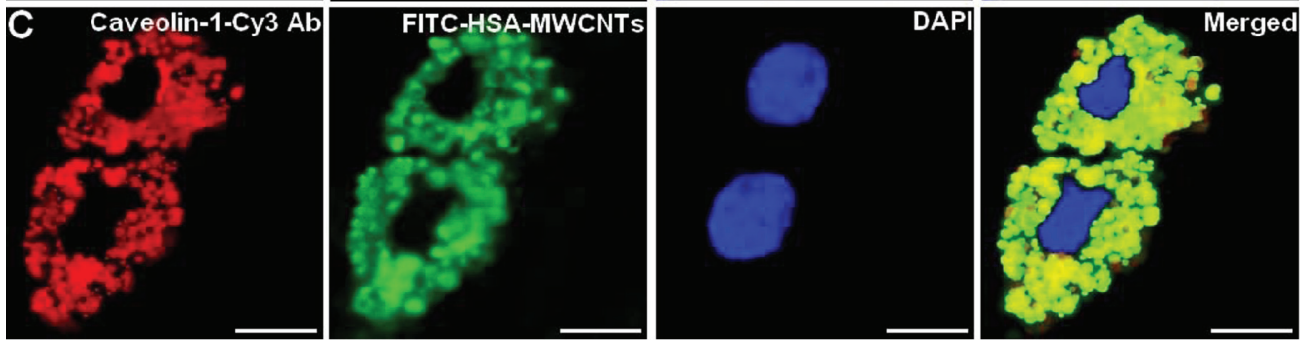

CRL-4020

Hep G2

Figure 2 HSA-MWCNTs in vitro endocytosis mechanism in human liver cancer cells. (A) Co-localization of the Cy-gp60 antibody and FITC-HSA-MWCNTs in HepG2 cells. (B) co-localization of the Cy-gp60 antibody and FITC-HSA-MWCNTs in hepatocyte epithelial cells. (C) co-localization of the caveolin-I-Cy antibody and FITC-HSAMWCNTs in HepG2 cells. Results are representative of three experiments.

Notes: Scale bar: $20 \mu \mathrm{m}$ in all panels. Reprinted with permission from lancu C, Mocan L, Bele C, et al. Enhanced laser thermal ablation for the in vitro treatment of liver cancer by specific delivery of multiwalled carbon nanotubes functionalized with human serum albumin. Int J Nanomedicine. 20II;6:129-141.52 Copyright @ 201 I Dove Medical Press.

Abbreviations: Ab, antibody; DAPI, 4'-6-diamidino-2-phenylindole; FITC, fluorescein isothiocyanate; HSA, human serum albumin; MWCNTs, multiwalled carbon nanotubes.

In Figure $2 \mathrm{~A}$, fourth panel, nearly complete co-localization of green fluorescence and red fluorescence was evident as yellow in the merged image. This finding demonstrates that albumin bound to MWCNTs was incorporated into vesicles containing gp60 as a membrane protein, validating HSA-MWCNTs specificity for gp60 receptors. In contrast, as seen in Figure 2B, no significant co-localization in the normal cells was observed for cy3-gp60 antibody and HSA-FITC-MWCNTs incubated under the same circumstances. Therefore, based on these data, we showed that HSA-MWCNTs can act as specific and sensitive site-targeted nanosystems against gp60 receptor located on the liver cancer cell's membrane (Figure 3).

In the next step, HepG2 cells and hepatocytes (control) were treated with HSA-MWCNTs at various concentrations and at various incubation times, and further irradiated using a $2 \mathrm{~W}, 808 \mathrm{~nm}$ laser beam. The post-irradiation apoptotic rate of HepG2 cells treated with HSA-MWCNTs was $88.24 \%$ (for $50 \mathrm{mg} / \mathrm{L}$ ) at 60 seconds, while at 30 minutes the rate increased to $92.34 \%$ (50 mg/L). Significantly lower necrosis rates were obtained when human hepatocytes were treated with HSA-MWCNTs in a similar manner.

\section{In vitro nanophotothermolysis of \\ Burkitt's lymphoma}

SWCNTs bound to CD22 monoclonal antibody were shown to retain their photonic properties and selectively internalized anti-CD22+ mab human Burkitt's lymphoma in vitro. ${ }^{54}$ The cells were incubated with CNTs coupled to the anti-CD22 monoclonal antibodies (mAb) (RFB4) and further exposed to an $808 \mathrm{~nm}$ laser $\left(5 \mathrm{~W} / \mathrm{cm}^{2}\right)$ for 7 minutes and pulsed for the next 12 hours with [3H] thymidine to assess cell viability. In another paper, the same authors reported a significantly increased necrosis rate in RFB4-CNT-treated Daudi cells compared with unconjugated CNTs. The viability of the RFB4-CNT-treated Daudi cells was significantly reduced after exposure to NIR light $(P<0.0001) .{ }^{55}$

\section{In vitro nanophotothermolysis of breast cancer}

BT474 breast cancer cells were treated with SWCNTs fabricated using a methane-based chemical-vapor-deposition method at various concentrations and further irradiated 




Figure 3 The proposed mechanism for albumin receptor mediated internalization of HSA-MWCNT inside HepG2 cells (schematic drawing). MWCNT internalization involves the selective uptake of HSA-MWCNT with the aid of albumin (GP60) receptors. This usually begins with the formation of caveolar invaginations on the plasma membrane surface. These pits are called caveosomes. The vesicles then transform into early endosomes. Matured (late) endosomes receive internalized material en route to lysosomes, usually from early endosomes in the endocytic pathway and most of the associated receptors circulate back to the cell membrane. Late endosomes mediate a final set of sorting events prior to delivery of material to lysosomes. Lysosomes are the last compartment of the endocytic pathway. The MWCNTs are released inside the cytoplasm forming clusters and HSA is digested by lysosomes.

Abbreviations: Ab, antibody; HSA, human serum albumin; MWCNT, multiwalled carbon nanotube.

( $800 \mathrm{~nm}$ and $200 \mathrm{~mW} / \mathrm{cm}^{2}$ ), killing all the cells in less than 60 seconds. ${ }^{56}$ The authors showed the existence of bubbles around the dead cells, further indicating that the boiling was due to SWCNTs explosions. These "nanobombs" were produced as a result of heat confinement in bundles of SWCNTs and the presence of adsorbed water molecules. The local heat rapidly caused extreme pressures in between the bundles of SWCNTs, resulting in further "nanoexplosions." These explosions were adjusted by changes in the intensity of NIR.
Another group covalently attached a monoclonal antibody that is specific for Her2, a clinically important marker on breast cancer cells, on the surface of CNTs. ${ }^{30}$ These conjugates were further tested for their ability to induce breast cancer cells necrosis following exposure to NIR light $\left(4 \mathrm{~W} / \mathrm{cm}^{2}\right)$ for 9 minutes. Cell death was detected 24 hours later by staining the trypsin-detached cells with FITC-labeled HER81, an anti-Her2 mAb. Subsequently, the distribution of dead cells among the two cell populations was evaluated by flow cytometry according to Her2 positivity and providone 
iodine staining. The authors found that under the laser exposure noted above, about $38.8 \%$ of Her $2+$ target cells were killed compared with less than $10 \%$ of the nontargeted Her2- cells. The same report showed that anti-Her2-CNTs can be actively endocytosed by breast cancer cells.

Various strategies for the fabrication of CNTs bioconjugates with a role in photothermal ablation of breast cancer cells have been proposed. Xiao et al have tested a HER2 IgY-SWCNTs complex for both detection and selective destruction of malign cells in an in vitro model consisting of HER2-expressing SK-BR-3 cells and HER2-negative MCF-7 cells..$^{40,57}$ In fact, NIR irradiation with a $808 \mathrm{~nm}$ laser at $5 \mathrm{~W} / \mathrm{cm}^{2}$ for 2 minutes of SK-BR-3 cells treated with the HER2 IgY-SWCNTs complex showed extensive cellular thermal necrosis ( $95 \%$ of the cells were necrotic); in contrast, the viability of SK-BR-3 cells treated with SWCNTs alone or untreated and of MCF-7 cells treated with the HER2 IgYSWCNTs complex was not affected (the cells were 100\% viable). Based on the temperature measurements of the IgYSWCNTs complex solution at the nanotube concentration of $4 \mathrm{mg} / \mathrm{L}$ that exhibited an increase of $\sim 14^{\circ} \mathrm{C}$ in the bulk solution, the authors stated that the temperature increase in the surrounding environment would not cause damage to normal cells that do not bind to the SWCNTs-containing complex in the short time period (2 minutes).

\section{In vivo photothermal ablation of tumors mediated by CNTs}

The "holy grail" in CNTs-mediated targeted cancer phototherapy ${ }^{36}$ is to deliver high doses of active bionanomolecules to tumor sites for maximum treatment efficacy while minimizing side effects to normal organs ${ }^{58}$ (Figure 4).

\section{In vivo nanophotothermolysis of squamous cell carcinoma}

In a study conducted by Huang et al SCCVII tumors in $\mathrm{C} 3 \mathrm{H} / \mathrm{HeN}$ mice were exposed to $785 \mathrm{~nm}$ laser after intratumoral injection of SWCNTs with different wavelengths and SWCNTs dose combinations. ${ }^{59}$ Following the treatment, the temperatures of the tumor tissue during laser irradiation were monitored. Tumor responses (tumor volume monitoring and survival parameters) were evaluated daily after treatment up to day 45 to assess the efficiency of the treatment. Surprisingly, the authors found that in mice treated with $1 \mathrm{mg} / \mathrm{mL} \mathrm{SWCNTs}$ and further irradiated with $200 \mathrm{~mW} / \mathrm{cm}^{2}$, the tumors became clinically silent (impalpable) 1 day after treatment. In stark contrast, tumors in the negative control group, SWCNTs-only group, and laser-only groups continued to grow. After the treatment, the authors found that at 45 days, five mice were still alive in the $200 \mathrm{~mW} / \mathrm{cm}^{2}+$ $1 \mathrm{mg} / \mathrm{mL}$ group, three mice in the $200 \mathrm{~mW} / \mathrm{cm}^{2}+0.5 \mathrm{mg} / \mathrm{mL}$ group, two mice in the $200 \mathrm{~mW} / \mathrm{cm}^{2}+0.1 \mathrm{mg} / \mathrm{mL}$ group and one mouse in the $100 \mathrm{~mW} / \mathrm{cm}^{2}+0.5 \mathrm{mg} / \mathrm{ml}$ group (initially there were eight mice in each group) (log rank test among the groups: $<0.005)$ The authors also reported a temperature increase on average, by $18.5^{\circ} \mathrm{C}$ in $200 \mathrm{~mW} / \mathrm{cm}^{2}+1 \mathrm{mg} / \mathrm{mL}$ group, $14.2^{\circ} \mathrm{C}$ in $200 \mathrm{~mW} / \mathrm{cm}^{2}+0.5 \mathrm{mg} / \mathrm{mL}$ group, $11.7^{\circ} \mathrm{C}$ in $200 \mathrm{~mW} / \mathrm{cm}^{2}+0.1 \mathrm{mg} / \mathrm{mL}$ group, around $10^{\circ} \mathrm{C}$ in all the three $100 \mathrm{~mW} / \mathrm{cm}^{2}+$ drug groups, and 6.1 and $7.9^{\circ} \mathrm{C}$ in the 100 and $200 \mathrm{~mW} / \mathrm{cm}^{2}$ laser-only groups, respectively, at the end of treatment. The authors concluded that squamous cell carcinomas can be safely eradicated by photothermal therapy using intratumoral injection of SWCNTs and $785 \mathrm{~nm}$ NIR irradiation at a moderate light irradiance $\left(200 \mathrm{~mW} / \mathrm{cm}^{2}\right.$ and $120 \mathrm{~J} / \mathrm{cm}^{2}$ ).

\section{In vivo nanophotothermolysis of prostate cancer}

Ghosh et al showed that DNA encasement of MWCNTs increases local heat production (which is generated with a linear dependence on irradiation time and laser power) following NIR irradiation and that these DNA-encased nanoconjugates can be used to safely eradicate a tumor mass in vivo. ${ }^{60}$ The authors found that DNA encasement resulted in a threefold reduction in the concentration of MWCNTs required to
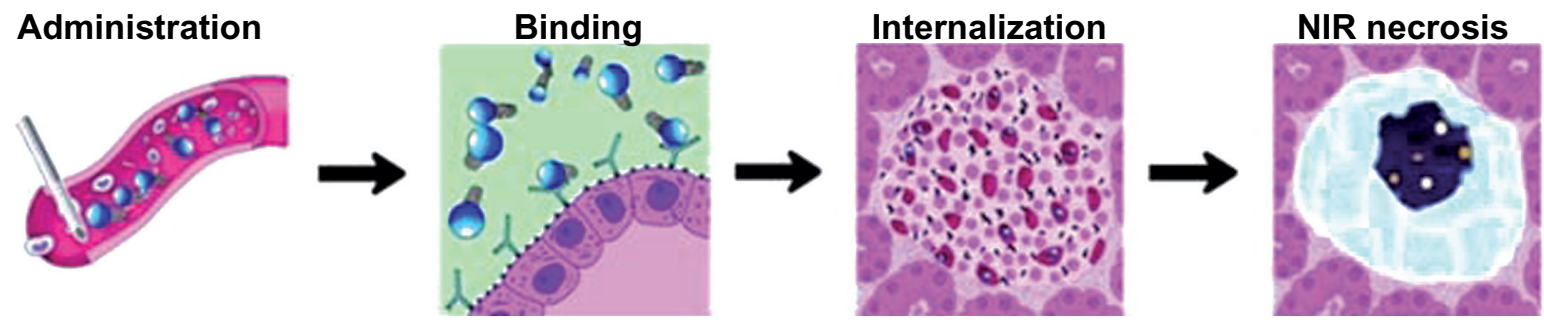

Figure 4 Schematic illustration of the in vivo Ab-CNTs mediated ablation of malign tumors.

Note: Reprinted with permission from Mocan L, Tabaran F, Mocan T, et al. Selective ex-vivo photothermal ablation of human pancreatic cancer with albumin functionalized multiwalled carbon nanotubes. Int J Nanomedicine. 201 I;6(I):915-928. ${ }^{19}$ Copyright @ 201 I Dove Medical Press.

Abbreviations: Ab, antibody; CNTs, carbon nanotubes. 
increase temperature of bulk solution by $10^{\circ} \mathrm{C}$. After intratumoral administration of MWCNTs $(500 \mathrm{mg} / \mathrm{L})$ combined with external laser irradiation at $1064 \mathrm{~nm}, 2.5 \mathrm{~W} / \mathrm{cm}^{2}$, the authors reported complete necrosis of prostate cancer PC3 xenograft tumors. In contrast, tumors that received only MWCNTs injection or laser irradiation showed growth rates indistinguishable from that of untreated controls. The healthy surrounding tissue was not affected. The presented results showed that DNA-encased MWCNTs are more efficient at converting NIR irradiation into heat compared with nonencased MWCNTs therefore may be safely used for the in vivo selective thermal ablation of malignant tissue.

\section{In vivo nanophotothermolysis of kidney cancer}

MWCNTs response to NIR was used for the thermal destruction of kidney cancer in vitro and in vivo. ${ }^{61}$ In this research, MWCNTs were efficient in thermal ablation of tumors with low laser powers $\left(3 \mathrm{~W} / \mathrm{cm}^{2}\right)$ and very short treatment times (30-seconds). The tumor involution following the treatment depended on the concentration of MWCNTs administered. At a dose of $100 \mu \mathrm{g}$ of MWCNTs, complete tumor regression without recurrence for 12 weeks after the treatment (a single 30 -second treatment with $3 \mathrm{~W} / \mathrm{cm}^{2} \mathrm{NIR}$ ) was observed in $80 \%$ of the mice. In contrast, tumor regression was not seen in untreated mice, mice treated with MWCNTs alone, or mice treated with laser-generated NIR alone. The authors reported an increase in the temperature to $76^{\circ} \mathrm{C}$ in MWCNTs-treated tumor tissue after laser irradiation while the peak temperature measured in laser-irradiated tumors was $46^{\circ} \mathrm{C}$ in the absence of MWCNTs.

\section{In vivo nanophotothermolysis of liver cancer}

In one study, a group of rabbits, all implanted with the same form of hepatic VX2 liver cancer, was used as test subjects. ${ }^{62}$ Kentera functionalized SWCNTs were further injected directly into their tumors and then immediately placed inside a radiofrequency field (600 W for 2 minutes) and positioned so that the tumor would get maximum field energy. The experiment resulted in the malignant tumor cells being completely destroyed in the experimental group with no noted adverse side effects in the test subjects.

\section{Ex vivo photothermal ablation of tumors mediated by CNTs}

Several authors have evaluated histological samples with and without photothermal-mediated nanoparticles treatment using photothermal scanning cytometry for color-coded imaging, spectral identification, and quantitative detection of individual nanoparticles. The obtained data highlighted the promise of photothermal cytometry in the analysis of low-absorption samples and mapping of the distribution of various individual nanoparticles that would be impossible with existing assays. ${ }^{63}$ One group investigated the optical and thermal response to laser radiation of representative tissue biopsies containing MWCNTs. The rate of temperature increase and peak temperature for tissue pieces containing MWCNTs was much greater compared with tissue biopsies without MWCNTs at all measurement locations. ${ }^{64}$

\section{Ex vivo nanophotothermolysis of pancreatic cancer}

Considering the important role of albumin in tumor metabolism, ${ }^{63}$ we have used human albumin bound to MWCNTs for the ex vivo selective targeting of pancreatic cancer. Since ethical limitations made the selectivity and therapeutic potential of these nanocompounds in patients impossible to test, we have designed an original model of living pancreatic cancer harvested and preserved in a similar manner as for pancreatic transplantation. We used ex vivo-perfused pancreatic specimens that had been surgically removed from patients with ductal adenocarcinoma (Figure 5). On this model, the intra-arterial administration of albumin conjugated with MWCNTs (200 mg/L) specifically induced the release of this nanobioconjugate inside the malign tissue via the "capillary bed."

We showed that extensive and selective tumoral necrosis was obtained when the living pancreas underwent laser irradiation ( 30 minutes, $808 \mathrm{~nm}, 5 \mathrm{~W} / \mathrm{cm}^{2}$ ) after the administration of HSA-MWCNTs via the greater pancreatic artery. In this experiment, all the existing situations met in surgical practice were replicated.

\section{Biodistribution and pharmacokinetics of CNTs}

Despite their unique features, the toxicity and biological interactions of CNTs represent a major concern, with several authors pointing to their similarity to asbestos fibers. ${ }^{65,66}$ Many factors attributed to CNTs such as biofunctionalization, length, concentration, duration of exposure, and methods of dispersion have been associated with CNTs toxicity in both in vitro and in vivo studies. ${ }^{67}$

To date, few in vitro experiments assert that oxidative stress from CNTs is a major result of toxicity. However, the number studies suggesting that CNTs are nontoxic in vivo 

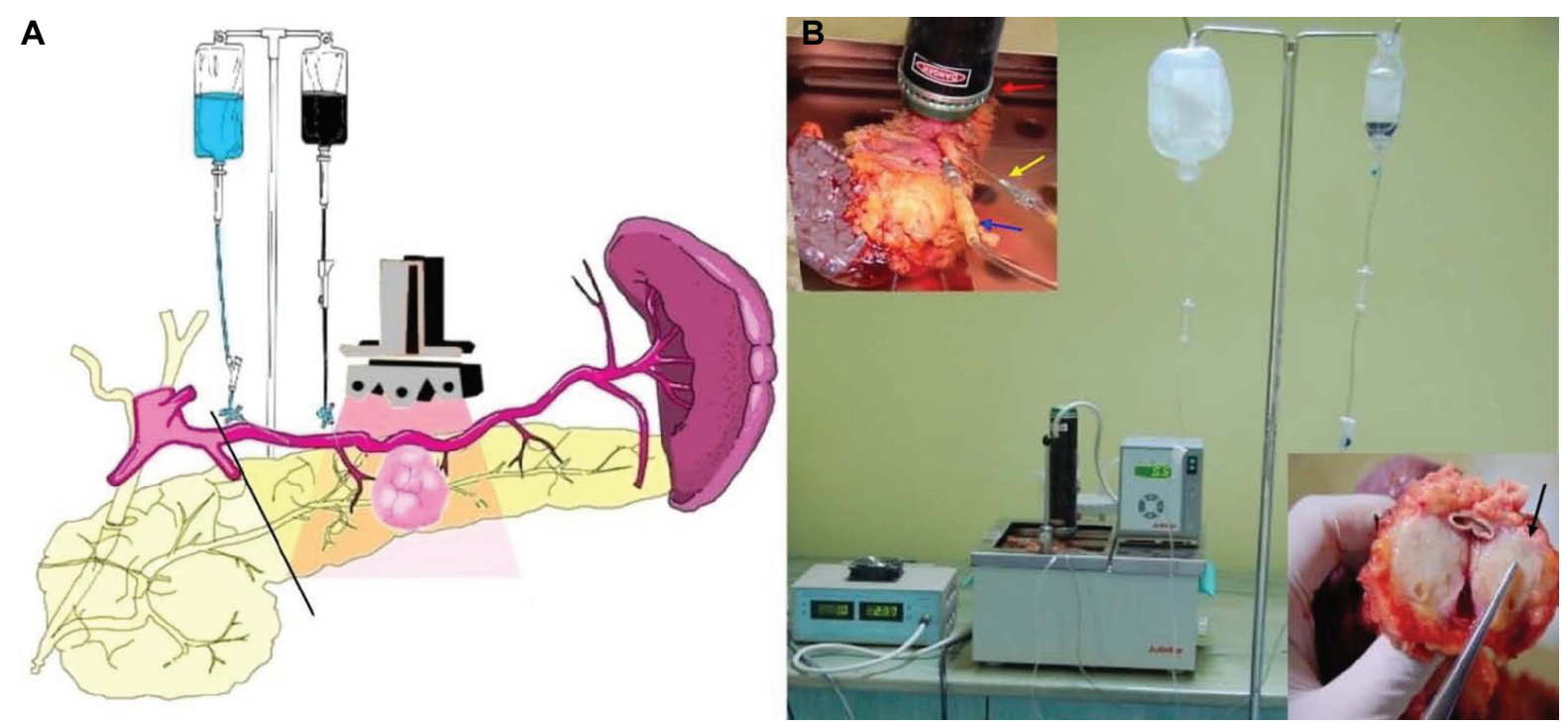

Figure 5 (A) Schematic illustration of the ex vivo thermal ablation of human pancreatic adenocarcinoma on surgically resected specimens from the body and tail of the pancreas and spleen. (B) The proposed system of ex vivo laser ablation of human pancreatic cancer cells.

Notes: Red arrow: laser diode placed above the tumoral mass; blue arrow: the intra-arterial administration of HSA-MWCNTs-FITC in the pancreatic magna artery; yellow arrow: the intra-arterial administration of Custodiol ${ }^{\circledR}$ solution in the spleno-pancreatic artery; black arrow: macroscopic aspect of tumor mass after photothermal treatment). Reprinted with permission from Mocan L, Tabaran F, Mocan T, et al. Selective ex-vivo photothermal ablation of human pancreatic cancer with albumin functionalized multiwalled carbon nanotubes. Int J Nanomedicine. 201 I;6(1):915-928. ${ }^{19}$ Copyright (C) 2011 Dove Medical Press.

Abbreviations: FITC, fluorescein isothiocyanate; HSA, human serum albumin; MWCNTs, multiwalled carbon nanotubes.

outnumbers those proposing otherwise. It has been stated that toxicity of CNTs is negligible in mice with chronic exposure to CNTs. ${ }^{68}$ Following administration of PEGylated SWCNTs, changes in neutrophil count were lower than counts from those mice treated with PEGylated oxidized SWCNTs. This fact suggests that varying functionalization can modify toxicity. ${ }^{69}$

Following intravenous administration in mice, CNTs are excreted in the urine. Moreover, CNTs deposits were found in the liver, spleen, and lungs..$^{10}$ Other studies indicate that CNTs deposits are mostly found in the excretory systems like the bladder, kidneys, and large bowel. ${ }^{70,71}$

\section{Future perspectives}

From a clinical perspective, the CNTs-mediated photothermal ablation of cancers implies ultrasound identification of the tumor and its vascular supply, intra-arterial administration of the functionalized CNTs, and external laser irradiation. All these could be safely achieved in humans by means of minimally invasive surgery, with major benefits for the patient. Thus, from a surgical point of view, by laparoscopy (also known as minimally invasive surgery or videoscopic surgery) it is possible to identify the main artery supply of the tumor (using intraoperative Doppler ultrasound) and to intra-arterially administer CNTs solution followed by laser irradiation. Moreover in future mini-laser diodes could be developed for proper access in the abdominal cavity through laparoscopic trocars. The advantages of such a minimally invasive approach are numerous and include: reduced postoperative pain, reduced hospitalization, quicker return to social activities, and, ultimately, improved cosmetics and reduced wound complications. As an alternative to laparoscopy, natural orifice translumenal endoscopic surgery and a percutaneous approach under ultrasound/CT guidance may also be used for the specific delivery of bionanosystems inside tumors.

\section{Conclusion}

CNTs provide opportunities for designing and tuning properties that are not possible with other types of therapeutic vectors and have a bright future as a new generation of photothermal agents. With the increasing capital of knowledge and the development of technology, we expect rapid advancement in the field of thermal ablation of human cancer mediated by biofunctionalized CNTs in the years to come. Efficient strategies for targeting ligands on CNTs for tumor nanophotothermolysis are also expected to further enhance treatment efficacy. Nevertheless, further research is required for the careful assessment of unexpected toxicities and biodistribution in early stage clinical trials.

\section{Acknowledgments}

The authors would like to acknowledge grant support from Romanian Society of Nanomedicine and Romanian Ministry 
of Research (CNMP-PNCDI II: NANOPAN 41-009 and NANOHEP 42-115.)

\section{Disclosure}

The authors declare no conflicts of interest in relation to this paper.

\section{References}

1. Banerjee D, Harfouche R, Sengupta S. Nanotechnology-mediated targeting of tumor angiogenesis. Vasc Cell. 2011;3(1):3.

2. Bekyarova E, Ni Y, Malarkey EB, et al. Applications of carbon nanotubes in biotechnology and biomedicine. J Biomed Nanotechnol. 2005; 1(1):3-17.

3. Liang XJ, Chen C, Zhao Y, Jia L, Wang PC. Biopharmaceutics and therapeutic potential of engineered nanomaterials. Curr Drug Metab. 2008;9(8):697-709.

4. Liu Z, Kiessling F, Gätjens J. Advanced nanomaterials in multimodal imaging: design, functionalization, and biomedical applications. J Nanomater. 2010:51

5. Ciofani G, Ricotti L, Danti S, Moscato S, Nesti C. Investigation of interactions between poly-L-lysine-coated boron nitride nanotubes and $\mathrm{C} 2 \mathrm{C} 12$ cells: up-take, cytocompatibility, and differentiation. Int J Nanomedicine. 2010;5:285-298.

6. Hosseini A, Sharifzadeh M, Rezayat SM, et al. Benefit of magnesium-25 carrying porphyrin-fullerene nanoparticles in experimental diabetic neuropathy. Int J Nanomedicine. 2010;5:517-523.

7. Bharali DJ, Khalil M, Gurbuz M, Simone TM, Mousa SA. Nanoparticles and cancer therapy: A concise review with emphasis on dendrimers. Int J Nanomedicine. 2009;4:1-7.

8. Zhao D, Zhao X, Zu Y, et al. Preparation, characterization, and in vitro targeted delivery of folate-decorated paclitaxel-loaded bovine serum albumin nanoparticles. Int J Nanomedicine. 2010;5:669-677.

9. Sun TP, Shieh HL, Ching CTS, et al. Carbon nanotube composites for glucose biosensor incorporated with reverse iontophoresis function for noninvasive glucose monitoring. Int J Nanomedicine. 2010;5:343-349.

10. Yang ST, Wang X, Jia G, et al. Long-term accumulation and low toxicity of single-walled carbon nanotubes in intravenously exposed mice. Toxicol Lett. 2008;181(3):182-189.

11. Kang B, Yu D, Dai Y, Chang S, Chen D, Ding Y. Cancer-cell targeting and photoacoustic therapy using carbon nanotubes as "bomb" agents. Small. 2009;5(11):1292-1301.

12. Kam NW, O'Connell M, Wisdom JA, Dai H. Carbon nanotubes as multifunctional biological transporters and near-infrared agents for selective cancer cell destruction. Proc Natl Acad Sci U S A. 2005;102(33): 11600-11605.

13. Xu Y, Mahmood M, Fejleh A, et al. Carbon-covered magnetic nanomaterials and their application for the thermolysis of cancer cells. Int J Nanomedicine. 2010;5:167-176.

14. Day ES, Bickford LR, Slater JH, Riggall NS, Drezek RA, West JL. Antibody-conjugated gold-gold sulfide nanoparticles as multifunctional agents for imaging and therapy of breast cancer. Int J Nanomedicine. 2010;5:445-454

15. Borja-Cacho D, Jensen EH, Saluja AK, Buchsbaum DJ, Vickers SM. Molecular targeted therapies for pancreatic cancer. Am J Surg. 2008; 196(3):430-441.

16. Iancu, Cornel, Ilie IR, Georgescu CE, et al. Applications of nanomaterials in cell stem therapies and the onset of nanomedicine. Particulate Science and Technology. 2009;27(6):562-574.

17. Pepene CE, Kasperk CH, Pfeilschifter J, et al. Effects of triiodothyronine on the insulin-like growth factor system in primary human osteoblastic cells in vitro. Bone. 2001;29(6):540-546.

18. Kam NW, Dai H. Carbon nanotubes as intracellular protein transporters: generality and biological functionality. J Am Chem Soc. 2005;127(16) 6021-6026.
19. Mocan L, Tabaran F, Mocan T, et al. Selective ex-vivo photothermal ablation of human pancreatic cancer with albumin functionalized multiwalled carbon nanotubes. Int J Nanomedicine. 2011;6(1):915-928.

20. Menard-Moyon C, Kostarelos K, Prato M, Bianco A. Functionalized carbon nanotubes for probing and modulating molecular functions. Chem Biol. 2010;17(2):107-115.

21. Zhang Y, Bai Y, Yan B. Functionalized carbon nanotubes for potential medicinal applications. Drug Discov Today. 2010;15(11-12): 428-435.

22. Hadidi N, Kobarfard F, Nafissi-Varcheh N, Aboofazeli R. Optimization of single-walled carbon nanotube solubility by noncovalent PEGylation using experimental design methods. Int J Nanomedicine. 2011;6:737-746.

23. Kolacyak D, Ihde J, Merten C, Hartwig A, Lommatzsch U. Fast functionalization of multi-walled carbon nanotubes by an atmospheric pressure plasma jet. J Colloid Interface Sci. 2011;359(1):311-317.

24. Zheng X, Zhou F. Noncovalent functionalization of single-walled carbon nanotubes by indocyanine green: Potential nanocomplexes for photothermal therapy. J Xray Sci Technol. 2011;19(2):275-284.

25. Khazaei A, Rad MN, Borazjani MK. Organic functionalization of singlewalled carbon nanotubes (SWCNTs) with some chemotherapeutic agents as a potential method for drug delivery. Int $J$ Nanomedicine. 2010;5:639-645.

26. Mattson MP, Haddon RC, Rao AM. Molecular functionalization of carbon nanotubes and use as substrates for neuronal growth. $J \mathrm{Mol}$ Neurosci. 2000;14(3):175-182.

27. Kam NW, Liu Z, Dai H. Functionalization of carbon nanotubes via cleavable disulfide bonds for efficient intracellular delivery of siRNA and potent gene silencing. J Am Chem Soc. 2005;127(36):12492-12493.

28. Dumortier H, Lacotte S, Pastorin G, et al. Functionalized carbon nanotubes are non-cytotoxic and preserve the functionality of primary immune cells. Nano Lett. 2006;6(7):1522-1528.

29. Venturelli E, Fabbro C, Chaloin O, et al. Antibody covalent immobilization on carbon nanotubes and assessment of antigen binding. Small. 201. Epub 2011 May 24

30. Marches R, Mikoryak C, Wang RH, Pantano P, Draper RK, Vitetta ES. The importance of cellular internalization of antibody-targeted carbon nanotubes in the photothermal ablation of breast cancer cells. Nanotechnology. 2011;22(9):095101.

31. Ruggiero A, Villa $\mathrm{CH}$, Holland JP, et al. Imaging and treating tumor vasculature with targeted radiolabeled carbon nanotubes. Int J Nanomedicine. 2010;5:783-802.

32. Zharov VP, Galitovskaya EN, Johnson C, Kelly T. Synergistic enhancement of selective nanophotothermolysis with gold nanoclusters: potential for cancer therapy. Lasers Surg Med. 2005;37(3):219-226.

33. Pantarotto D, Briand JP, Prato M, Bianco A. Translocation of bioactive peptides across cell membranes by carbon nanotubes. Chem Commun (Camb). 2004;(1)(1):16-17.

34. Kam NW, Liu Z, Dai H. Carbon nanotubes as intracellular transporters for proteins and DNA: an investigation of the uptake mechanism and pathway. Angew Chem Int Ed Engl. 2006;45(4):577-581.

35. Kostarelos K, Lacerda L, Pastorin G, et al. Cellular uptake of functionalized carbon nanotubes is independent of functional group and cell type. Nat Nanotechnol. 2007;2(2):108-113.

36. Liu Z, Tabakman SM, Chen Z, Dai H. Preparation of carbon nanotube bioconjugates for biomedical applications. Nat Protoc. 2009;4(9): 1372-1382.

37. Holt BD, Dahl KN, Islam MF. Quantification of uptake and localization of bovine serum albumin-stabilized single-wall carbon nanotubes in different human cell types. Small. 2011. Epub 2011 May 31.

38. Heister E, Neves V, Tîlmaciu C, et al. Triple functionalisation of singlewalled carbon nanotubes with doxorubicin, a monoclonal antibody, and a fluorescent marker for targeted cancer therapy. Carbon. 2009;47(9): 2152-2160.

39. Levi-Polyachenko NH, Merkel EJ, Jones BT, Carroll DL, Stewart JH 4th. Rapid photothermal intracellular drug delivery using multiwalled carbon nanotubes. Mol Pharm. 2009;6(4):1092-1099. 
40. Xiao Y, Gao X, Taratula O, et al. Anti-HER2 IgY antibody-functionalized single-walled carbon nanotubes for detection and selective destruction of breast cancer cells. BMC Cancer. 2009;9:351.

41. Wang CH, Huang YJ, Chang CW, Hsu WM, Peng CA. In vitro photothermal destruction of neuroblastoma cells using carbon nanotubes conjugated with GD2 monoclonal antibody. Nanotechnology. 2009;20(31): 315101 .

42. Liu Z, Tabakman S, Welsher K, Dai H. Carbon nanotubes in biology and medicine: in vitro and in vivo detection, imaging and drug delivery. Nano Res. 2009;2(2):85-120.

43. Lu Y, Sega E, Leamon CP, Low PS. Folate receptor-targeted immunotherapy of cancer: mechanism and therapeutic potential. Adv Drug Deliv Rev. 2004;56(8):1161-1176.

44. Biris AS, Boldor D, Palmer J, et al. Nanophotothermolysis of multiple scattered cancer cells with carbon nanotubes guided by time-resolved infrared thermal imaging. J Biomed Opt. 2009;14(2):021007-021007-6.

45. Fisher JW, Sarkar S, Buchanan CF, et al. Photothermal response of human and murine cancer cells to multiwalled carbon nanotubes after laser irradiation. Cancer Res. 2010;70(23):9855-9864.

46. Markovic ZM, Harhaji-Trajkovic LM, Todorovic-Markovic BM, et al. In vitro comparison of the photothermal anticancer activity of graphene nanoparticles and carbon nanotubes. Biomaterials. 2011;32(4): 1121-1129.

47. Wang CH, Chiou SH, Chou CP, Chen YC, Huang YJ, Peng CA. Photothermolysis of glioblastoma stem-like cells targeted by carbon nanotubes conjugated with CD133 monoclonal antibody. Nanomedicine. 2011;7(1):69-79.

48. Di Stefano G, Fiume L, Bolondi L, Lanza M, Pariali M, Chieco P. Enhanced uptake of lactosaminated human albumin by rat hepatocarcinomas: implications for an improved chemotherapy of primary liver tumors. Liver Int. 2005;25(4):854-860.

49. Schilling U, Friedrich EA, Sinn H, Schrenk HH, Clorius JH, Maier-Borst W. Design of compounds having enhanced tumour uptake, using serum albumin as a carrier - Part II. In vivo studies. Int J Rad Appl Instrum B. 1992;19(6):685-695.

50. Sinn H, Schrenk HH, Friedrich EA, Schilling U, Maier-Borst W. Design of compounds having an enhanced tumour uptake, using serum albumin as a carrier. Part I. Int J Rad Appl Instrum B. 1990;17(8):819-827.

51. Stehle G, Wunder A, Sinn H, et al. Pharmacokinetics of methotrexatealbumin conjugates in tumor-bearing rats. Anticancer Drugs. 1997;8(9): 835-844.

52. Iancu C, Mocan L, Bele C, et al. Enhanced laser thermal ablation for the in vitro treatment of liver cancer by specific delivery of multiwalled carbon nanotubes functionalized with human serum albumin. Int J Nanomedicine. 2011;6:129-141.

53. Tiruppathi C, Song W, Bergenfeldt M, Sass P, Malik AB. Gp60 activation mediates albumin transcytosis in endothelial cells by tyrosine kinasedependent pathway. J Biol Chem. 1997;272(41):25968-25975.

54. Chakravarty P, Marches R, Zimmerman NS, et al. Thermal ablation of tumor cells with antibody-functionalized single-walled carbon nanotubes. Proc Natl Acad Sci U S A. 2008;105(25):8697-8702.

55. Marches R, Chakravarty P, Musselman IH, et al. Specific thermal ablation of tumor cells using single-walled carbon nanotubes targeted by covalently-coupled monoclonal antibodies. Int J Cancer. 2009;125(12): 2970-2977.

International Journal of Nanomedicine

\section{Publish your work in this journal}

The International Journal of Nanomedicine is an international, peerreviewed journal focusing on the application of nanotechnology in diagnostics, therapeutics, and drug delivery systems throughout the biomedical field. This journal is indexed on PubMed Central, MedLine, CAS, SciSearch $\AA$, Current Contents ${ }^{\circledR} /$ Clinical Medicine,
56. Panchapakesan B, Lu S, Sivakumar K, Taker K, Cesarone G, Wickstrom E. Single-wall carbon nanotube nanobomb agents for killing breast cancer cells. Nanobiotechnology. 2005;(2):133-139.

57. Xiao Y, Gao X, Gannot G, et al. Quantitation of HER2 and telomerase biomarkers in solid tumors with IgY antibodies and nanocrystal detection. Int J Cancer. 2008;122(10):2178-2186.

58. Al Faraj A, Fauvelle F, Luciani N, et al. In vivo biodistribution and biological impact of injected carbon nanotubes using magnetic resonance techniques. Int J Nanomedicine. 2011;6:351-361.

59. Huang N, Wang H, Zhao J, Lui H, Korbelik M, Zeng H. Single-wall carbon nanotubes assisted photothermal cancer therapy: animal study with a murine model of squamous cell carcinoma. Lasers Surg Med. 2010;42(9):638-648.

60. Ghosh S, Dutta S, Gomes E, et al. Increased heating efficiency and selective thermal ablation of malignant tissue with DNA-encased multiwalled carbon nanotubes. ACS Nano. 2009;3(9):2667-2673.

61. Moon HK, Lee SH, Choi HC. In vivo near-infrared mediated tumor destruction by photothermal effect of carbon nanotubes. ACS Nano. 2009;3(11):3707-3713.

62. Gannon CJ, Cherukuri P, Yakobson BI, et al. Carbon nanotube-enhanced thermal destruction of cancer cells in a noninvasive radiofrequency field. Cancer. 2007;110(12):2654-2665.

63. Nedosekin DA, Shashkov EV, Galanzha EI, Hennings L, Zharov VP. Photothermal multispectral image cytometry for quantitative histology of nanoparticles and micrometastasis in intact, stained and selectively burned tissues. Cytometry A. 2010;77(11):1049-1058.

64. Picou L, McMann C, Elzer PH, Enright FM, Biris AS, Boldor D. Spatio-temporal thermal kinetics of in situ MWCNT heating in biological tissues under NIR laser irradiation. Nanotechnology. 2010;21:435101.

65. Firme III CP, Bandaru PR. Toxicity issues in the application of carbon nanotubes to biological systems. Nanomedicine. 2010;6(2):245-256.

66. Poland CA, Duffin R, Kinloch I, et al. Carbon nanotubes introduced into the abdominal cavity of mice show asbestos-like pathogenicity in a pilot study. Nat Nanotechnol. 2008;3(7):423-428.

67. Magrez A, Kasas S, Salicio V, et al. Cellular toxicity of carbon-based nanomaterials. Nano Lett. 2006;6(6):1121-1125.

68. Kostarelos K, Bianco A, Prato M. Promises, facts and challenges for carbon nanotubes in imaging and therapeutics. Nat Nanotechnol. 2009; 4(10):627-633

69. Schipper ML, Nakayama-Ratchford N, Davis CR, et al. A pilot toxicology study of single-walled carbon nanotubes in a small sample of mice. Nat Nanotechnol. 2008;3(4):216-221.

70. Yang ST, Wang X, Jia G, et al. Long-term accumulation and low toxicity of single-walled carbon nanotubes in intravenously exposed mice. Toxicol Lett. 2008;181(3):182-189.

71. Liu Z, Davis C, Cai W, He L, Chen X, Dai H. Circulation and long-term fate of functionalized, biocompatible single-walled carbon nanotubes in mice probed by Raman spectroscopy. Proc Natl Acad Sci U S A. 2008; 105(5):1410-1415.

Journal Citation Reports/Science Edition, EMBase, Scopus and the Elsevier Bibliographic databases. The manuscript management system is completely online and includes a very quick and fair peer-review system, which is all easy to use. Visit http://www.dovepress.com/ testimonials.php to read real quotes from published authors. 